\title{
Dominant cone dystrophy starting with blue cone involvement
}

Mary J van Schooneveld, Loe N Went, Jendo A Oosterhuis

\begin{abstract}
The results of ophthalmological and colour vision studies are reported on 13 patients from a family with a dominant cone dystrophy spanning seven generations. The onset of visual deterioration occurred in the third or fourth decade. In the early stages of the disease, when visual acuity is still close to normal, a severe defect in the blue sensitivity is already present, as measured by spectral sensitivity curves and other tests suitable for the detection of tritan defects. In our opinion this condition represents a distinct entity with autosomal dominant inheritance.
\end{abstract}

Cone dystrophies form a heterogeneous group of disorders characterised by progressive impairment of visual acuity and colour vision, photophobia, and a low or absent photopic electroretinogram. ${ }^{1-6}$ Symptoms may start in early childhood or as late as the fifth decade, the great majority of cases presenting within the first two decades of life. ${ }^{46} \mathrm{~A}$ considerable proportion of cone dystrophies are inherited, usually in an autosomal dominant fashion, but occasionally as a sex-linked ${ }^{78}$ or autosomal recessive ${ }^{49}$ disorder.

Fundus changes, if present, consist of patchy macular mottling, a bull's eye lesion, or more widespread atrophic changes. At the onset of symptoms most patients do not show any fundus abnormalities. ${ }^{6}$
Colour vision disturbances are reported to be usually of the red-green type in the early stages. ${ }^{6}$ Later on non-specific disturbances are found, and eventually all colour discrimination is lost. Pearman $e t a l^{3}$ found in their study of nine affected members of a family with autosomal dominant cone dystrophy that any type of colour vision defect could occur in the early stages, though a red-green defect was usually found. In one patient a strong tritan defect was found in addition to red-green disturbances.

In this paper we report on a family with autosomal dominant cone dystrophy with selective early blue cone involvement which differs from previously described cases. Loss of visual acuity occurs relatively late in life, around the age of 20 to 35 years, and is only slowly progressive. In many patients the fundus appears normal.

\section{Methods}

Ophthalmic examinations included assessment of visual acuity, slit-lamp examination, and ophthalmoscopy in all 13 patients; electroretinography (ERG) in 10, fluorescein angiography and visual field examination in six.

The following colour vision tests were employed: the Ishihara, the Hardy-Rand-Rittler (HRR) and 'Birch'10 plate tests; the Farnsworth Panel D15 and Lanthony desaturated Panel D15 arrangement tests; the Nagel anomaloscope; an
Netherlands Ophthalmic Research Institute, Amsterdam

$M \mathrm{~J}$ van Schooneveld

Department of Human Genetics, State University of Leiden L N Went

\section{Department of} Ophthalmology, State University of Leiden, The Netherlands J A Oosterhuis

Correspondence to: Professor Dr L N Went Terweeweg 142, $2341 \mathrm{CX}$ Oegstgeest, The Netherlands. Accepted for publication 14 November 1990

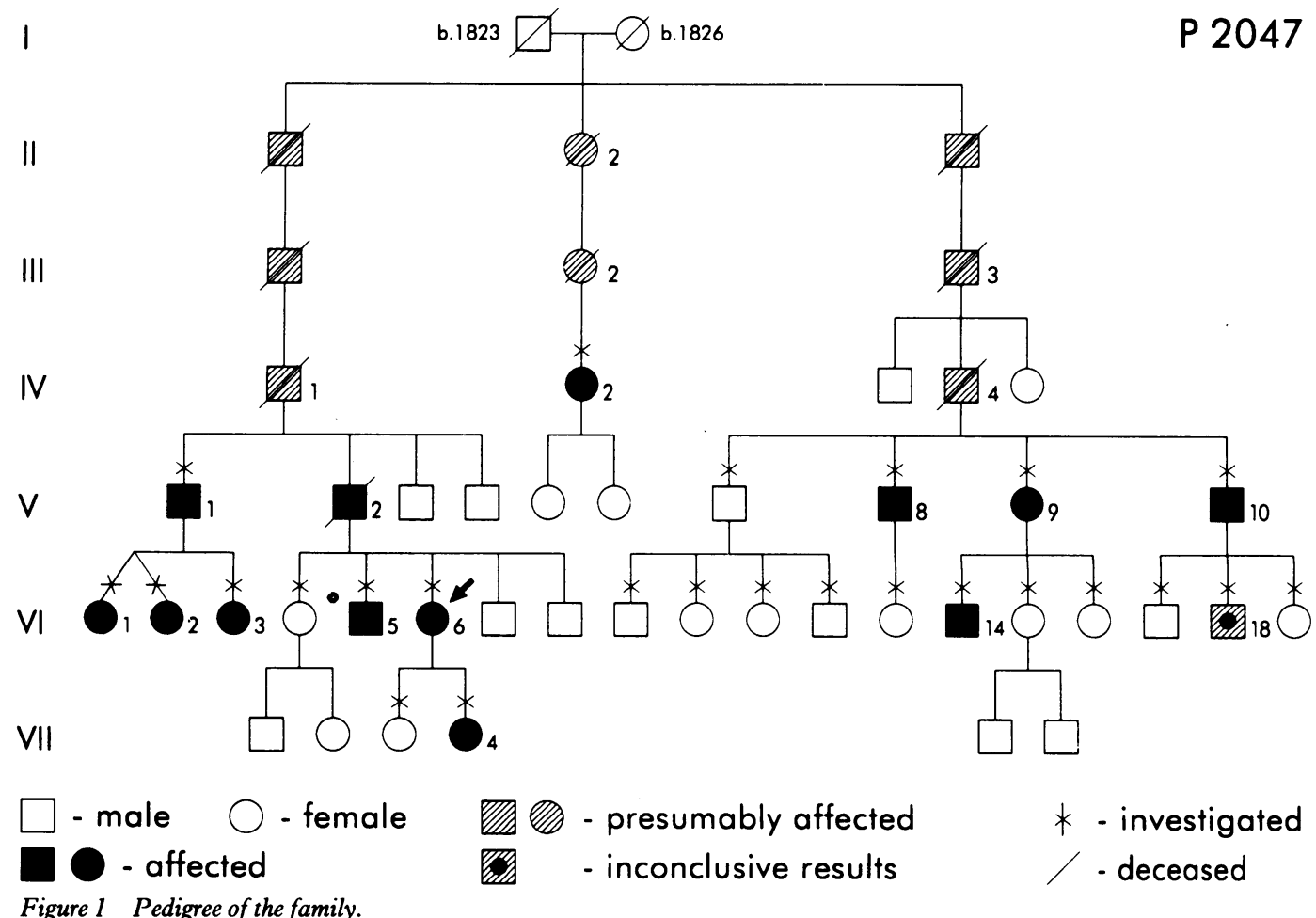

Figure 1 Pedigree of the family. 
instrument for measuring spectral sensitivity curves $^{11} 12$ and a so called 'tritan test' ${ }^{13}$ The Birch plate test consists of nine plates, five of which are specifically designed to detect a tritan defect. The 'tritan test' has a $1^{\circ}$ flickering (frequency 0.5 Hertz) blue $(462 \mathrm{~nm})$ test field on a $14^{\circ}$ intense yellow background with a luminance of $3700 \mathrm{~cd} / \mathrm{m}^{2}$. The blue test field may be presented attenuated with a 2.6 neutral density filter or unattenuated. Tritan defective individuals fail to see the attenuated stimulus, even after a long exposure, while normal individuals see it within 30 to 60 seconds of adaptation.

\section{Results}

In Figure 1 an abbreviated version of the pedigree is given. Seven generations are involved dating back as far as 1823 . The family history on members of the second, third, and fourth generation (photophobia and severe impairment of visual acuity, starting gradually in later adult life) is highly suggestive of the presence of the abnormal gene. With one exception (IV.2) only individuals from the fifth to the seventh generation were alive and available for examination. From the pedigree the autosomal dominant mode of inheritance is obvious: males and females are equally affected, father to son transmission is present, and roughly half the children of affected individuals are affected themselves. A few case histories revealing the typical abnormalities and the marked variability of the disorder will be presented.

\section{CASE HISTORIES}

VI.6, the index case, was born in 1950 . At the age of 5 she was operated on for strabismus. At age 12 her corrected visual acuity was $0 \cdot 2$ OD and $1.0 \mathrm{OS}$, with a normal fundus aspect. The right eye was considered to be amblyopic. These findings were unchanged at age 21 and 26 . When 31 she visited the Eye Clinic in Leiden because of reading problems. Corrected visual acuity of the left eye was 0.9 and fluorescein angiography showed minute window defects in the maculae.

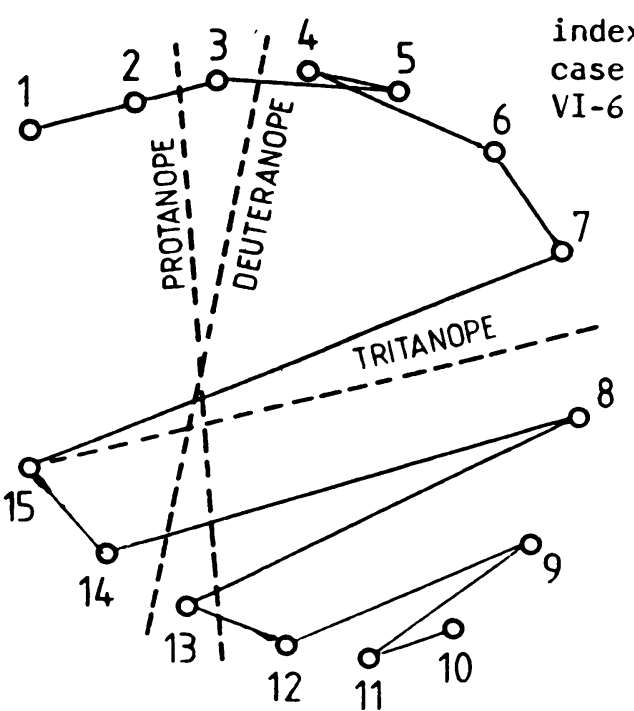

Figure 2 Results of the F15 arrangement test on the index case (VI.6).
Goldmann kinetic perimetry revealed a mild relative central scotoma for both eyes. The ERG showed a normal rod response and a decreased cone response $(50 \%$ of the normal amplitude). The F15 arrangement test revealed a classical tritan response (Fig 2), in accordance with the almost complete absence of blue sensitivity on the spectral luminosity curves (between 2 and 3 logarithms below the normal reading) and a tritan response with the 'tritan test'. She accepted a practically normal red-green setting with the Nagel anomaloscope, though she could not distinguish any of the plates of the Ishihara and HRR tests presumably because of the central scotoma. In this patient central vision started to decrease relatively late in life; at the age of 35 her visual acuity was still $0 \cdot 8$.

VI.5, a brother $1 \frac{1}{2}$ years older than the index case, had corrected visual acuity of 0.8 in both eyes at the age of 18 , with a normal fundus appearance. At age 32 his visual acuity had decreased to finger counting at $2 \mathrm{~m}$ for both eyes, with a large central scotoma. The patient was photophobic. Ophthalmological examination at age 34 revealed pallor of the optic discs and marked pigmentary mottling in the macular area. Angiography disclosed bilateral symmetrical window defects (Fig 3). The electrooculogram (EOG) was normal; the ERG showed a normal rod response, while the cone mediated response was reduced to $25 \%$ of the normal amplitude. The patient could not perform any of the colour vision tests.

V.9, a 50-year-old woman, noted decreasing visual acuity in her early 30 s. At age 32 corrected visual acuity was $0.2 \mathrm{OD}$ and $0.3 \mathrm{OS}$. Fluorescein angiography showed no abnormalities except for myopic changes. Colour vision was reported to be greatly disturbed. At the age of 50 visual acuity in both eyes had decreased to counting fingers. We noted a marked discrepancy between functional deficit and funduscopic findings, since ophthalmoscopy revealed only subtle granular pigmentation of the macula. On angiography minute window defects of the retinal pigment epithelium were seen. There was marked photophobia. The ERG showed mainly scotopic responses; with red stimuli no responses

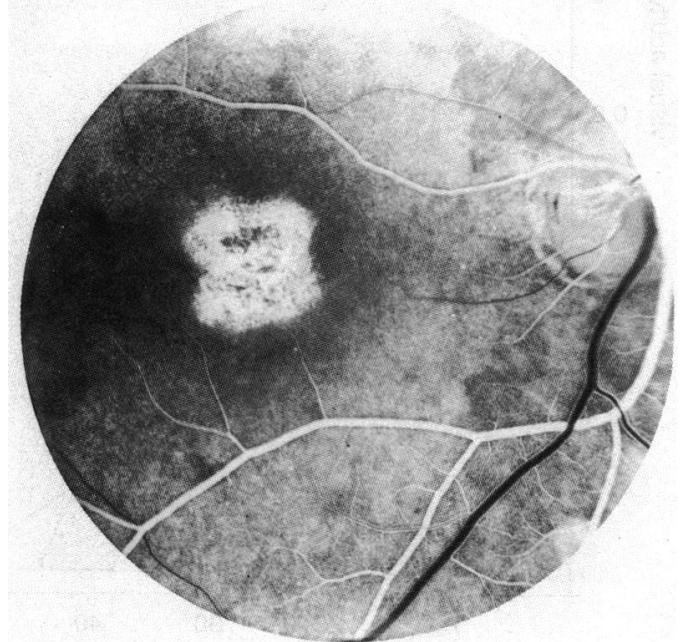

Figure 3 Fluorescein angiography of VI.5 showing extensive window defect. 
Table 1 Data of 13 individuals with dominant cone dystrophy

\begin{tabular}{|c|c|c|c|c|c|c|c|c|c|}
\hline \multirow{2}{*}{$\begin{array}{l}\text { Pedigree } \\
\text { number }\end{array}$} & \multirow[b]{2}{*}{ Sex } & \multirow[b]{2}{*}{$A g e^{l}$} & \multirow{2}{*}{$\frac{\begin{array}{l}\text { Visual } \\
\text { acuity }\end{array}}{\text { OD OS }}$} & $\begin{array}{l}\text { Refractive } \\
\text { error }^{3}\end{array}$ & \multirow[b]{2}{*}{ Fundus } & \multirow[b]{2}{*}{$E R G^{s}$} & \multirow[b]{2}{*}{ Birch $^{6}$} & \multirow[b]{2}{*}{$T T^{\top}$} & \multirow[b]{2}{*}{ Curves } \\
\hline & & & & $O D O S$ & & & & & \\
\hline IV.2 & $\mathrm{F}$ & 76 & LP /LP & $-16 /-16$ & ++ & + & * & $\star$ & $\star$ \\
\hline V.1 & M & 62 & $\overline{C F} / \overline{C F}$ & $0 / 0$ & ++ & + & $\star$ & $\star$ & $\star$ \\
\hline V.2 & M & 44 & $\mathrm{CF} / \mathrm{CF}$ & $-7 /-9$ & $t^{9}$ & & & & \\
\hline V.8 & M & 53 & $\mathrm{CF} / \mathrm{CF}$ & $-9 /-10$ & - & + & $\star$ & * & * \\
\hline V.9 & $F$ & 50 & $\mathrm{CF} / \mathrm{CF}$ & $-4 /-5$ & + & + & * & $\star$ & * \\
\hline V10 & M & 43 & $0.3 / 0 \cdot 3$ & $-4 /-4$ & - & & 4 & $\mathrm{t}$ & \\
\hline VI.1 & $\mathbf{F}$ & 33 & $0 \cdot 2 / 0 \cdot 3$ & $+1 / 0$ & - & + & 5 & $\mathbf{t}$ & $\mathrm{t}$ \\
\hline VI. 2 & $\mathbf{F}$ & 33 & $0.8 / 0.6$ & $-1 /-1$ & - & + & 3 & $\mathrm{t}$ & $\mathrm{t}$ \\
\hline VI.3 & $\mathbf{F}$ & 26 & $0.5 / 0.6$ & $0 / 0$ & - & + & 3 & $\mathrm{t}$ & $\mathrm{t}$ \\
\hline VI. 5 & M & 34 & $\mathrm{CF} / \mathrm{CF}$ & $-1 /-1$ & ++ & + & 夫 & $\star$ & ^ \\
\hline VI. 6 & $\mathrm{~F}$ & 35 & $0.2 / 0.8$ & $0 / 0$ & + & + & 5 & $\mathrm{t}$ & $\mathrm{t}$ \\
\hline VI.14 & M & 26 & $0.8 / 0.8$ & $-1 /-1$ & - & - & 2 & $\mathrm{t}$ & $\mathbf{t}$ \\
\hline VII.4 & $\mathbf{F}$ & 8 & $1 \cdot 0 / 1 \cdot 0$ & $0 / 0$ & - & & 2 & $\mathrm{t}$ & \\
\hline
\end{tabular}

1 Refers to age at last examination.

2 Decimal acuity following Snellen notation; $L P=$ light perception; $C F=$ counting fingers.

3 Spheric equivalent in dioptres.

4 Normal aspect or only dubious changes like absent foveolar reflex; $+=$ discrete atrophic changes at funduscopy or fluorescein angiography; $++=$ marked pigmentary dystrophy or areolar atrophy.

5 Electroretinography: $+=$ absent or reduced photopic ERG; $-=$ normal ERG.

6 Birch test: the number of tritan plates missed (maximally 5).

7 Tritan test.

8 Spectral sensitivity curves, with and without yellow bleaching; ${ }^{\star}$ test impossible due to low vision. 9 In this man there were also myopic macular changes like Fuchs's spot.

were obtained. Colour vision testing had become impossible.

VI.14, the 26-year-old son of V.9, had noted some difficulty in distinguishing blue from green. Corrected visual acuity was 1.0 in both eyes at the age of 20 and 0.8 at the age of 26 . Ophthalmoscopy showed normal optic discs and normal maculae except for absent foveolar reflexes. Both the photopic ERG (also with red stimuli) and the scotopic ERG were normal. However, the results of the F15, HRR, and Birch tests were suggestive of impairment of the blue cone sensitivity. This was definitely proved by the results of the 'tritan test' and by the luminosity curves, which showed an almost complete loss of blue cone sensitivity (more than 2 logarithms below normal). Not a single mistake was made with the Ishihara and with the redgreen plates of the HRR test.

In Table 1 a summary is given of the clinical and colour vision findings in all 13 affected individuals. Myopia of at least 4 dioptres was found in five of them. The macular appearance was normal or inconspicuous in about half of the patients, but distinctive in two: VI.5 had exten-

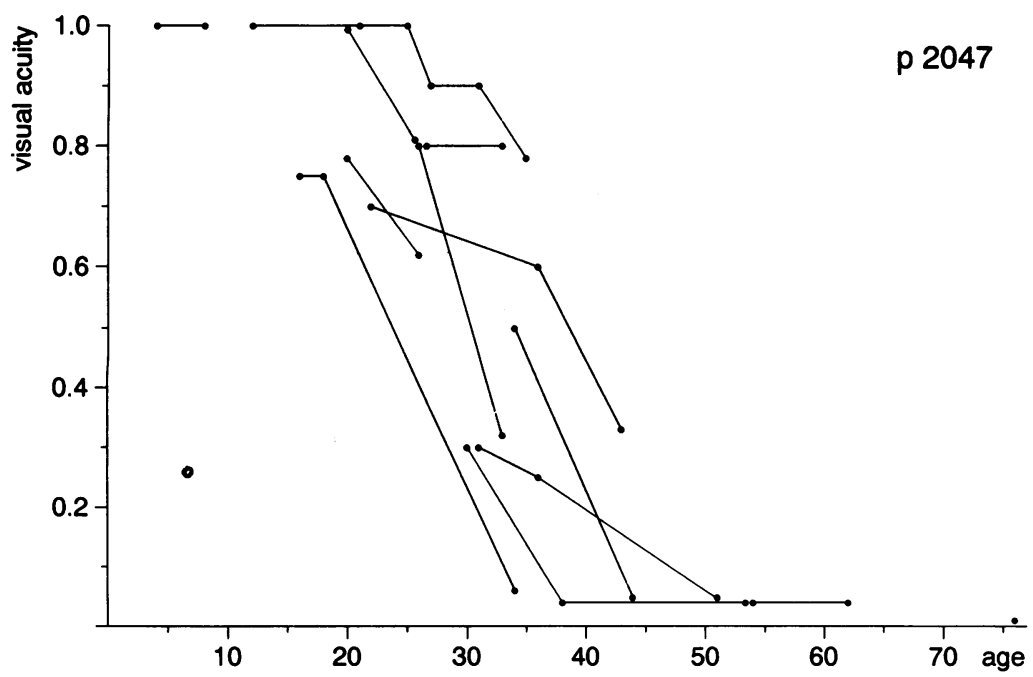

Figure 5 Visual acuity related to age in 13 patients. Points connected by a line are different measurements on the same patient.

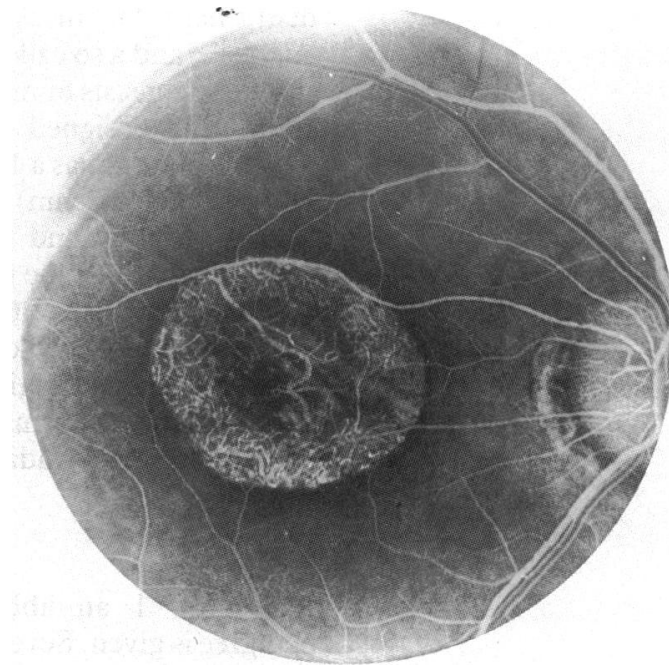

Figure 4 Fluorescein angiography of V.1 showing areolar atrophy of the macula.

sive loss of the central retinal pigment epithelium (Fig 3), and V.1 had areolar atrophy of the macula (Fig 4). IV.2 had definite areolar atrophy in both maculae, but also widespread atrophic changes due to her high myopia of 16 dioptres. She had a history of progressive loss of colour vision starting very early in life, and her photopic ERG was almost absent at the age of 53; this was considered to be not compatible with high myopia only. The information on V.2, who died in 1970 at the age of 50 , was obtained from another ophthalmologist. His visual acuity had deteriorated from $0.5 \mathrm{OD}$ and $0 \cdot 1 \mathrm{OS}$ at the age of 34 to counting fingers at the age of 44 . His macular abnormalities (Fuchs's spot) could be ascribed to his myopia ( 7 and 9 dioptres respectively). Nevertheless, this man must have been a gene carrier, since two of his children are affected.

In 10 patients ERG studies were performed and in nine the photopic ERG was reduced or absent. Only in patient VI.14, with subnormal visual acuity was a normal ERG found, while with colour vision testing a tritan disturbance was present. This patient was therefore considered to be affected. It is to be expected that the ERG in this patient will become abnormal in time. The two brothers of V.1 and V.2 as well as the two youngest sons of V.2 could not be examined because they were living abroad. They were said to be without any visual complaints.

In Fig 5 the visual acuity in the better eye is plotted against age for the 13 affected individuals. Although there is considerable variation at any given age, visual loss has a tendency to start in the third or fourth decade, usually leading to loss of central vision in the fourth or fifth decade. Visual acuity of 0.8 or more was present in four affected family members, the oldest being 35 years, but one member (VI.5) had already a nearly complete loss of central vision at the age of 34 years. The decrease of visual acuity was remarkably slow, for instance from 1.0 to 0.8 in nine years (VI.6) and from 0.7 to 0.3 in 22 years (V.10). Central vision was lost in all affected family members older than 50 years.

In the early stages of the disease a tritan defect was a consistent finding. The results of the three 
Figure 6 Spectral sensitivity curves of VI.2 compared with results of $a$ normal individual. A: Normal white background (retinal illumination 3.9 log troland). B: Yellow background (OG filter retinal illumination $5 \cdot 3 \log$ troland).

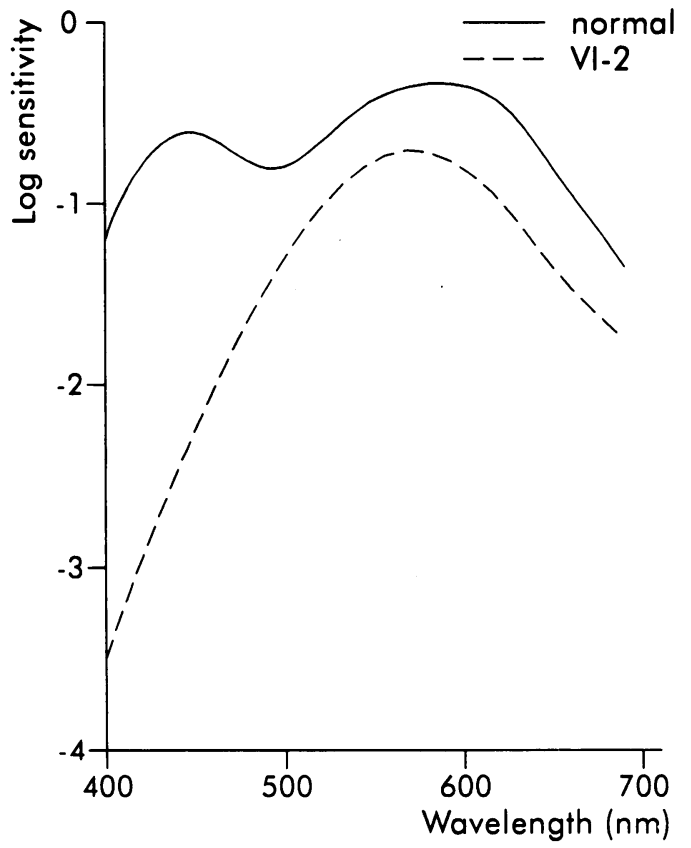

Figure 6A.

most specific tritan tests are listed in Table 1. The Ishihara plates were either correctly seen or non-specific errors were made. The HRR plates and the D-15 desaturated panel pointed to a tritan defect in four persons but gave almost normal results in two (VI.2 and VI.3); the visual acuity of the other patients was too low for us to perform these tests. Two patients (VI.2 and VI.6), who made numerous errors with the Ishihara plates presumably because of loss of central vision, chose a normal matching range with the Nagel anomaloscope. The spectral sensitivity curves were diagnostic for the absence of blue sensitivity (Fig 6 A, B).

\section{Discussion}

We describe a family with an autosomal dominantly inherited cone dystrophy associated with loss of blue cone function as an early sign. In this family the diagnosis of cone dystrophy is firmly established by the presence of the characteristic symptoms: loss of visual acuity, decreased or absent photopic ERG, photophobia, and colour vision deficiency.

Cone dystrophy can be associated with a normal aspect of the macula, but, if macular lesions develop, three types can be distinguished according to Krill ${ }^{4}$ : a bull's eye lesion, diffuse spotty pigment clumping, and choroidal vascular atrophy. In our family we found in seven patients a normal fundus appearance or only the absence of macular reflexes (Table 1). When maculopathy was visible, it presented mostly as diffuse pigment mottling. In two patients (IV.2 and V.1) extensive areolar macular atrophy was present, which in IV. 2 could also be related to her high myopia. The progression of the pigmentary maculopathy was remarkably slow: in two patients (V.8 and V.9) it hardly progressed over the course of 19 years, notwithstanding considerable loss of visual acuity.

Myopia of at least 4 dioptres was found in five of the affected 13 individuals, which may be a

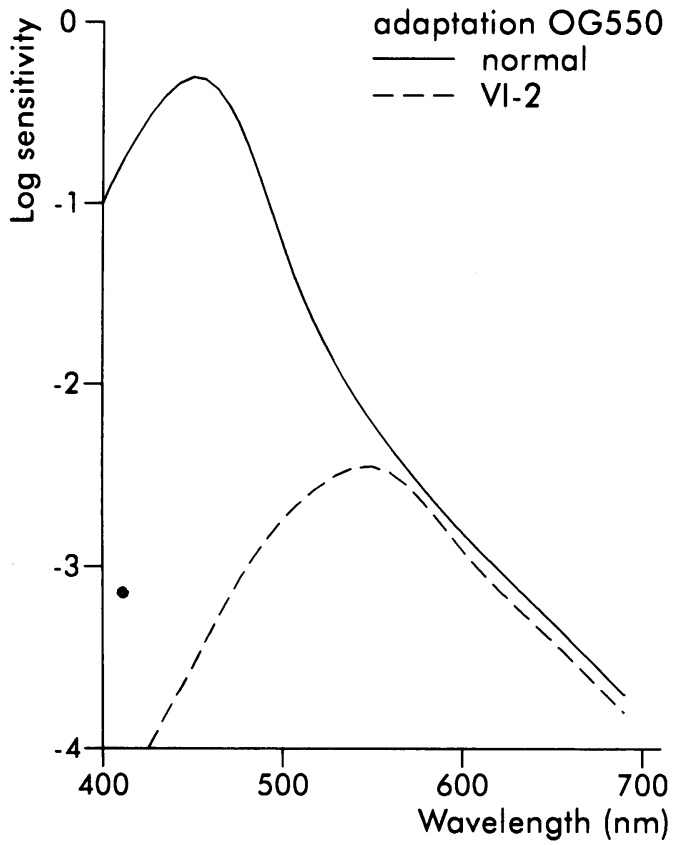

Figure $6 B$.

chance finding. However, cone dystrophy and myopia can be correlated, as was found in a large family with $\mathrm{X}$-linked cone dystrophy studied by some of us in which 15 of the 17 affected males and five of the 31 obligate carriers had high myopia. Myopia might also be a separate hereditary trait in our family, since the unaffected elder brother of V.8 also had high myopia. Visual acuity, fundus appearance, and colour vision testing in this 55-year-old man were entirely normal. In our family early blue cone involvement was a consistent and prominent diagnostic finding. All persons with sufficient vision to perform colour vision tests were found to be tritan defective (Table 1). Some even reported impaired blue-green discrimination from early childhood (IV.2, VI.3, and VI.5). In patient VI.14, with a normal photopic ERG, defective blue cone function and a mild reduction of visual acuity were the only obvious signs of the dominant cone dystrophy.

Since the condition starts insidiously, patients may not seek medical advice until visual acuity has dropped below 0.5 , because they adapt to their slowly developing visual handicap.

Marré $e t a l^{14}$ discussed a family with dominant cone dystrophy from which six individuals were examined in detail. Two of them had too low visual acuity to perform most of the colour vision tests. Apart from red-green disturbances Marré et al found blue cone involvement, except for their youngest patient, 12 years old, who had visual acuity 0.6 and normal colour vision test results. This contrasts with our family, in which tritan deficiency precedes loss of visual acuity. Furthermore, the condition in their family followed a more progressive course leading to substantial visual loss before the age of 20 .

Recently Bresnick et $a l^{15}$ described a family with 'autosomal dominant macular dystrophy with preferential short-wavelength sensitive cone involvement'. This title might suggest that the condition is comparable or identical to the one present in our family. However, in contrast 
to our family, the patients of Bresnick et al retained good visual acuity at mature age $(1.3$ in a 40 -year-old female and 1.0 in a 36-year-old male); moreover fluorescein angiography and conventional ERG were normal except for delayed implicit times. In their family the tritan defect is comparable to that in our family, but the ophthalmological findings are different. In conclusion, we believe that the family we have described with dominant cone dystrophy presenting initially as a tritan defect, represents a previously undescribed entity.

Unequal recombination or gene conversion of the genes on the long arm of the X-chromosome coding for the production of red and green cone visual pigments may cause congenital colour vision deficiency. ${ }^{16}$ DNA studies in a family with $\mathrm{X}$-linked cone dystrophy with predominant loss of red cone function in the early stages, recently described by Reichel et al, ${ }^{8}$ revealed a 6.5 kilobase deletion within the red cone pigment gene. This observation made us wonder whether the tritan gene on chromosome 7 could be responsible in our family for dominant cone dystrophy. Dr C J Weitz in Baltimore was willing to examine leucocyte DNA from our patient VI.2. He comments: 'The blue sensitive visual pigment locus was indistinguishable from that of normal controls by Southern blot and by denaturing gradient gel electrophoresis of "GCclamped" polymerase chain reaction products containing the exons and adjacent non-coding sequences. These results exclude any insertion or deletion larger than about 100 base pairs and make unlikely but do not exclude any smaller rearrangements or a point mutation within the gene' (Weitz C J, and Nathans J, personal communication 1990). Future DNA studies may enable us to make accurate subdivisions of the different cone dystrophies and could help us to understand the disease process in greater detail.

The authors are grateful to Mrs I van Leeuwen-Cornelisse for her help in the initial stages of the family study and to Dr C J Weitz for the DNA studies on patient VI.2.

1 Berson EL, Gouras P, Gunkel RD. Progressive cone degeneration, dominantly inherited. Arch Ophthalmol 1968; 80: 77-83.

2 Krill AE, Deutman AF. Dominant macular degenerations: the cone dystrophies. Am f Ophthalmol 1972; 73: 352-69.

3 Pearlman JT, Owen WG, Brounly DW, Sheppard JJ. Cone dystrophy with dominant inheritance. Am $\mathcal{F}$ Ophthalmol 1974; 77: 294-303.

4 Krill AE. Cone degenerations. In: Krill AE, Archer DB, eds. Krill's hereditary retinal and choroidal diseases: clinical charac-
teristics. New York: Harper and Row, 1977; 2: 421-78.

5 Ripps H, Noble KG, Greenstein VC, Siegel IM, Carr RE. Progressive cone dystrophy. Ophthalmology 1987; 94: 1401-9.

6 Weleber RG, Eisner A. Cone degeneration ('Bull's eye dystrophies') and color vision defects. In: Newsome DA, ed. Retinal dystrophies and degenerations. New York: Raven, 1988: 154; 162, 233-56.

7 Keunen JEE, Everdingen JAM van, Went LN, Oosterhuis $J A$, Norren D van. Color matching and retinal densitometry in patients and carriers of an X-linked progressive cone dystrophy. Arch Ophthalmol 1990; 108: 1713-9.

8 Reichel E, Bruce AM, Sandberg MA, Berson EL. An electroretinographic and molecular genetic study of $\mathrm{X}$-linked cone degeneration. Am 7 Ophthalmol 1989; 108: 540-7.

9 Gouras P, Eggers HM, MacKay CJ. Cone dystrophy, nyctalopia and supernormal rod responses. Arch Ophthalmol 1983; 101: 718-24.

10 Birch-Cox J. Design of diagnostic test for congenital and acquired colour vision defects. In: Verriest $G$ ed. Colour vision deficiencies. Basel: Karger, 1976: 4: 196-201.

11 Vries-de Mol EC de, Went LN, Norren D van, Pols LCW. Increment spectral sensitivity of hemizygotes and heteroIncrement spectral sensitivity of hemizygotes and heterozygotes for different classe
Ophthalmol 1978; 19: 224-8.

12 Went LN, Pronk N. The genetics of tritan disturbances. Hum Genet 1985; 69: 255-62.

13 Norren D van, Went LN. New test for the detection of tritan defects evaluated in two surveys. Vision Res 1981; 21 : 1303-6.

14 Marré M, Marré E, Zenker H-J, Fülle D. Colour vision in a family with dominant progressive cone dystrophy. In: E Marré, M Tostand, H-J Zenker, eds. Normal and pathologic colour vision. Halle: Martin Luther University, 1987: 53-9.

15 Bresnick GH, Smith VC, Pokorny J. Autosomal dominantly inherited macular dystrophy with preferential short-wavelength sensitive cone involvement. Am $\mathcal{F}$ Ophthalmol 1989 ; 108: 265-76.

16 Nathans J, Piantanida TP, Eddy RL, Shows TB, Hogness DS. Molecular genetics of inherited variation in human color vision. Science 1986; 232: 203-10. 